\title{
Siber Zorbalığın Öğrencilerin Akademik, Sosyal ve Duygusal Durumları Üzerindeki Etkisinin İncelenmesi*
}

\author{
An Investigation of Effects of Cyber Bullying on Students' \\ Academic, Social and Emotional States
}

\author{
Muharrem KESTEL**, Cenk AKBIYIK***
}

\begin{abstract}
Öz: Bu çalışmanın amacı, siber zorbalığa maruz kalan öğrencilerin maruz kalma durumlarının sosyal, duygusal ve akademik başarı açılarından incelenmesidir. Nitel bir durum çalışması olarak yürütülen çalışma Nevşehir'de bulunan bir ortaokulda gerçekleştirilmiştir. Çalışma, amaçlı örnekleme yöntemlerinden biri olan ölçüt örnekleme yöntemi ile belirlenen 12 öğrenci üzerinde yapılmıştır. Yarı yapılandırılmış görüş̧e yoluyla toplanan veriler betimsel analiz yöntemi ile çözümlenmiştir.

Çalışma sonucunda, öğrencilerin siber zorbalık hakkında ve siber zorbalıkla başa çıkmakla ilgili yeterince bilgi sahibi olmadıkları, velilerin ise öğrencileri bilgi ve iletişim teknolojilerini kullanırken yeterince kontrol etmedikleri bulgularına ulaşılmıştır. Katılımcılar daha çok sosyal paylaşım ve çevrim içi oyun ortamlarında siber zorbalığa maruz kalmaktadır. Öğrencilerin en sık küfür ve tehdit yollarıyla siber zorbalığa uğradıkları belirlenmiştir. Bulgulara göre siber zorbalığa maruz kalan öğrenciler korku, öfke ve tedirginlik gibi olumsuz duygular deneyimlemekte, yaşadıklarını çevreleri ile paylaşamamakta, aile ve arkadaş ilişkilerinde olumsuzluklarla karşı karşıya gelebilmektedir. Zorbalığa maruz kalma sonucunda öğrencilerin ders çalışma süreleri azalabilmekte ve akademik başarı düşmektedir. Uyku sorunları ve yalnız kalmaktan korkma, dışarı çıkmaktan korkma ve intihar düşüncesi ise araştırmanın diğer bulguları arasındadır.
\end{abstract}

Anahtar Kelimeler: Siber zorbalık, siber mağduriyet, akademik başarı, bilgi ve iletişim teknolojileri

\begin{abstract}
The main purpose of this study is to examine experiences of students who were exposed to cyber bullying from social, emotional and academic achievement viewpoints. The current study has been conducted in a secondary school, located in Nevsehir. The study has been carried out as a qualitative case study. Twelve students were selected by using the criterion sampling method, a purposive sampling method. Data was obtained through interviews and analysed using descriptive analysis technique.

The results of the study showed that students do not have adequate awareness about and coping strategies towards cyber bullying. Also parents of those children who were exposed to cyber bullying didn't control their children adequately while they were using information and communication technologies. It was also found that students were exposed to cyber victimization especially in social network and online game environments mostly by swearwords and threats but generally they didn't share these experiences with others. It was also revealed that students who were exposed to cyber bullying experienced negative emotions such as fear, anger, and nervousness. Lessened amount of study time and reduced rate of their academic achievement were also reported. Participants were not aware of the term "cyber bullying". Students stated they experienced insomnia and monophobia during the exposure to cyber bullying. Fear of going out, doubts about other people, difficulty in communicating with others, thought of suicide were also among the findings.

Keywords: Cyber bullying, cyber victimization, academic achievement, information and communication technologies
\end{abstract}

\section{Giriş}

Günümüzde iletişim teknolojilerinin hızla gelişmesi insanların birbirleri ile kurdukları iletişimin niteliğini de etkilemektedir. Örneğin kişilerin cebinde veya çantasında taşıyabildiği mobil iletişim teknolojileri, bireylerin farklı fiziksel ortamlarda bulunan, farklı kültürlerden insanlarla hızlı ve kolay biçimde iletişime geçebilmesine olanak sağlamaktadır. Diğer yandan bu

*Bu makale Erciyes Üniversitesi Eğitim Bilimleri Enstitüsü’nde yürütülen bir tez çalışmasından türetilmiştir.

**ìl Milli Eğitim Müdürlüğü, Nevşehir, Türkiye, kestelrooy@hotmail.com

***Erciyes Üniversitesi Eğitim Fakültesi, Kayseri, Türkiye, cenkakbiyik@gmail.com 
teknolojiler başkalarıyla iletişim kurabilmenin yanı sıra, bilgiye hızlı şekilde ulaşabilme, duygu ve düşünceleri elektronik ortamlarda ifade edebilme gibi firsatlar sunmaktadır. İnsan hayatına sağladığı katkılardan dolayı adeta vazgeçilmez konuma gelen bu teknolojilerle ilgili olarak yapılan araştırmalara göre çocuk ve ergenler cep telefonu, bilgisayar, İnternet, tablet bilgisayar gibi bilgi ve iletişim teknolojilerini yoğun biçimde kullanmaktadır (Erdur-Baker ve Kavşut, 2007).

Özellikle son yıllarda kullanımı giderek artan bilgi ve iletişim teknolojilerinin yanlış ve aşırı kullanımı çocuk ve ergenlerin gelişimleri üzerinde olumsuz etkilere sahip olabilmektedir. $\mathrm{Bu}$ olumsuz etkilerin belirlenmesi, engellenmesi ve ortadan kaldırılması yalnızca çocuk ve ergenler açısından değil, toplum düzeni açısından da büyük önem arz etmektedir (Şahin, Sarı, Özer ve Er, 2010). Bilgi ve iletişim teknolojilerinin yanlış kullanımı ne yazık ki bireylerin aile, okul, iş ve sosyal ilişkilerine zarar verebilmekte, bireyleri ev, iş ve okul yaşantılarında başarısızlık ve mutsuzluğa sürükleyebilmektedir.

Teknoloji kullanımından doğan sorunlar kapsamında bağımlllık, patolojik teknoloji kullanımı ve siber zorbalık gibi konular üzerinde araştırmalar ve tartışmalar sürdürülmektedir. İlgili araştırmacılardan biri olan Kınay (2012) da, diğer araştırmacıların önerileri doğrultusunda bireylerin internet kullanırken sergiledikleri tutumları ve davranışlarını belirlemek, sanal ortamlardaki insan davranışlarına dikkat çekmek, istenmeyen psikolojik ve sosyal sorunları önceden engelleyebilmek için patolojik teknoloji kullanımı ve siber zorbalık gibi konular üzerinde durulması gerektiği kanısında olduğunu belirtmektedir.

Zorbalı̆̆ın fiziksel ortamdan sanal ortama geçişi "siber zorbalık" olarak tanımlanan sorunu ortaya çıkarmaktadır (Belsey, 2006; Patchin ve Hinduja, 2006; Slonje ve Smith, 2008; Yaman, Eroğlu ve Peker, 2011). Siber zorbalık; bilgi ve iletişim teknolojilerinin kullanımı yoluyla bir kişi veya bir grup tarafından başkalarına zarar vermek amacıyla yapılan kasıtlı, tekrar eden ve saldırgan davranışlardır (Belsey, 2004). Siber zorbalık, sosyal ă̆, eposta, sesli mesaj, yazılı mesaj, görüntü paylaşımı, kişisel ağ siteleri, ă̆ günlükleri gibi çeşitli teknolojiler aracılığı ile yapılabilmekte, hakaret etme, tehdit etme, dedikodu yayma, uygunsuz görüntü paylaşma, başkasının adıyla sahte hesap açma, kişisel bilgileri izinsiz paylaşma gibi farklı biçimlerde karşımıza çıkabilmektedir. İnternet'in bir kitle iletişim aracı olarak kullanılmaya başlanması ve sosyal bir platforma dönüşmesi ile birlikte geleneksel zorbalık davranışları sanal ortama taşınmıştır (Arıcak, 2011; Türkoğlu, 2013). Dolayısı ile İnternet kullanan ergen ve gençler siber zorbalık davranışlarına maruz kalabilmektedir. $\mathrm{Bu}$ durum ise siber zorbalığı hem araştırmacılarca hem de eğitim kurumlarınca üzerinde durulması gereken bir soruna dönüştürmektedir (Willard, 2007).

Konu ile ilgili yürütülmüş olan bir araştırma sonuçlarına göre siber zorbalık, azımsanamayacak sayıda bireyin başına gelebilmektedir. Örneğin Amerika Birleşik Devletleri'ndeki ortaokul öğrencilerinin \%11'i siber zorbalığa maruz kalırken \%4'ü siber zorbalık yapmakta, \%7'si ise hem zorbalığa maruz kalmakta hem de zorbalık yapmaktadır (Kowalski ve Limber, 2007). Siber zorbalığa maruz kalmanın ise bireyler üzerinde çeşitli olumsuz etkileri bulunmaktadır. Beran ve Li (2007) tarafindan yapılan bir araştırma sonucuna göre siber mağduriyet ile okul başarısızlığı arasında da anlamlı ilişki bulunmuştur. Başka bir araştırma ise siber zorbalığa maruz kalan ortaokul öğrencilerinin kaygı ve depresyon düzeylerinin diğer akranlarına göre yüksek olduğunu ortaya koymuştur (Johnson, 2011). Ülkemizde yapılan çalışmalardan biri olan Erdur-Baker ve Tanrıkulu'nun (2010) yürüttükleri çalışmada ise siber mağduriyet ile depresyon arasında anlamlı bir ilişki olduğunu belirlenmiştir.

\section{Araştırmanın amacı}

Yürütülen bu araştırmanın temel amacı ortaokul öğrencilerinde siber zorbalığa maruz kalma durumunun incelenmesidir. Bu doğrultuda öğrencilerin siber zorbalığa maruz kalma durumu sosyal, duygusal ve akademik başarı açılarından incelenmiştir. 


\section{Araştırmanın önemi}

Yürütülen bu araştırma, siber zorbalığa maruz kalan öğrencilerin maruz kalma durumlarının ve bunun etkilerinin derinlemesine incelenerek ortaya konması yönünden anlamlıdır. Bu betimleme işi siber zorbalığa yönelik bilinci artırarak önlem almaya yönelik diğer çalışmalara 1şık tutacaktır. Bu çalışmanın ayrıca siber zorbalıkla ve etkileriyle başa çıkabilme becerilerini kazandırmaya yönelik eğitim programı ve öğretim tasarımı çalışmalarına yol göstermesi beklenmektedir.

\section{Yöntem}

\section{Araștırmanın modeli}

$\mathrm{Bu}$ çalışma ele alınan durumun derinlemesine incelenebilmesi amaciyla nitel bir durum çalışması olarak planlanıp yürütülmüştür.

\section{Çalışma grubu}

Araştırma Nevşehir'de bulunan bir ortaokulda gerçekleştirilmiştir. Çalışma grubuna alınan öğrenciler incelenen durum hakkında bilgi sahip olması gerektiğinden çalışmada amaçlı örnekleme yöntemlerinden biri olan ölçüt örnekleme tekniği tercih edilmiştir. Ölçüt örneklemede belirlenen ölçütleri karşılayan kişiler örnekleme alınırlar. Bu araştırmada ise siber zorbalığa maruz kalma, maruz kalınan siber zorbalığın süresi, gönüllü olma ve yaş ölçütleri kullanılarak belirlenen 12 öğrenci çalışma grubuna dâhil edilmiştir. Görüşme yapılan öğrencilerle ilgili temel bilgiler Tablo 1'de sunulmuştur.

Tablo 1. Görüşmeye Katılan Öğrencilerin Özellikleri

\begin{tabular}{ccc}
\hline Kat1limc1 & Maruz Kalınan Ortam & $\begin{array}{c}\text { Maruz Kalınan Süre } \\
(\text { Gün })\end{array}$ \\
\hline Ö1 & Sosyal Medya & $45-50$ \\
Ö2 & Online Oyun & 30 \\
Ö3 & Sosyal Medya & 7 \\
Ö4 & Sosyal Medya & 7 \\
Ö5 & Online Oyun & $12-13$ \\
Ö6 & Sosyal Medya & $30-35$ \\
Ö7 & Sosyal Medya & 10 \\
Ö8 & E-posta & 60 \\
Ö9 & Sosyal Medya & 7 \\
Ö10 & Cep Telefonu & 7 \\
Ö11 & Sosyal Medya & 25 \\
Ö12 & Sosyal Medya & 7 \\
\hline
\end{tabular}

Verilerin Toplanmast ve Analizi

Verileri toplama işinde nitel araştırmalarda sıklıkla kullanan tekniklerden biri olan yarı yapılandırılmış görüşme tekniği kullanılarak öğrencilerle bireysel görüşmeler yapılmıştır. Veri kaybını önlemek için, bütün görüşmeler kaydedilmiş, aynı zamanda görüşme sırasında notlar alınarak katılımcılar gözlenmiştir. Süreleri 16 ile 10 dakika arasında olan görüşmelerin ortalama süresi 13 dakikadır. Görüşme için yanıtlayıcıların kendilerini rahat hissedecekleri bir ortam sağlanmıştır.

Görüşme formu kavramsal çerçeve doğrultusunda alan yazın taraması yapılarak hazırlanmıştır. Ayrıca siber zorbalığa maruz kalmış üç öğrenci ile pilot çalışma yapılarak yeniden düzenlenmiş ve uzman görüşü alınarak forma son hali verilmiştir. Formda 29 adet açık uçlu madde yer almaktadır. 
Toplanan veriler betimsel analiz yöntemi ile çözümlenerek temalar çerçevesinde yorumlanmıştır. Temalar kavramsal çerçeve incelenerek oluşturulmuş, pilot görüşmelerin ardından gözden geçirilerek düzeltilmiştir.

Çalışmada analize temel oluşturan temalar şöyledir:

1. Siber zorbalığa maruz kalan öğrencilerin İnternet kullanım durumları

2. Siber zorbalık kavramı ve siber zorbalığa maruz kalma durumunda yapılması gerekenler hakkındaki görüşler

3. Maruz kalınan siber zorbalığın niteliği ve mağdurun tepkileri

4. Siber zorbalığa maruz kalan öğrencilerin yardım arama davranışları

5. Siber zorbalığa maruz kalmanın duygusal etkileri

6. Siber zorbalığa maruz kalan öğrencilerin aile ve arkadaşları ile ilişkileri

7. Siber zorbalığın akademik başarıya ve okul yaşamına etkisi

Betimsel analiz kapsamında elde edilen veriler açık bir biçimde betimlenmeye çalışı1mıştır. Görüşme yapılan bireylerin görüşlerini çarpıcı bir biçimde yansıtmak amacıyla doğrudan alıntılara sık sık yer verilmiştir. Ayrıca, bazı temalara ait cevaplalar tablolaştırılarak analizlerin okuyucular tarafından daha iyi anlaşılabilmesi sağlanmıştır.

Nitel araştırma yöntemiyle yapılan araştırmalarda konunun derinlemesine incelenmesi gerektiğinden araştırmacının katılımeı rolü ön plana çıkmaktadır. Araştırmacı dolaylı bilgi toplayan konumundan daha çok ilgili alanda zaman geçiren hedef kitleyi yakından tanıyan kişidir. Yürütülen çalışmada görüşmeler araştırmacı tarafında yapılmıştır. Aynı okulda öğretmen olarak görev yapan araştırmacı, yanıtlayıcıları yakından tanımaktadır ve onların kendilerini rahat ifade edebilmeleri için rahat ve güvenli bir atmosfer oluşturmuştur.

\section{Bulgular ve Yorum}

\section{Siber Zorbalı̆̆a Maruz Kalan Öğrencilerin Internet Kullanım Durumları}

Katılımcıların İnterneti ne sıklıkla kullandıkları ile ilgili veriler aşağıdaki tabloda gösterilmektedir.

Tablo 2. Öğrencilerin İnternet Kullanım Siklıkları

\begin{tabular}{|c|c|c|c|c|c|}
\hline & $\begin{array}{c}\text { Günlük } 4 \\
\text { saatten fazla } \\
\text { kullanırım }\end{array}$ & $\begin{array}{l}\text { Günlük 2-4 } \\
\text { saat } \\
\text { kullanırım }\end{array}$ & $\begin{array}{l}\text { Günlük 1-2 saat } \\
\text { kullanırım }\end{array}$ & $\begin{array}{l}\text { Günlük 1 } \\
\text { saatten az } \\
\text { kullanırım } \\
\end{array}$ & $\begin{array}{c}\text { Her gün } \\
\text { kullanmam }\end{array}$ \\
\hline Ö1 & & & & & $\mathrm{X}$ \\
\hline Ö2 & $X$ & & & & \\
\hline Ö3 & & $X$ & & & \\
\hline Ö4 & & & & & $X$ \\
\hline Ö5 & & $X$ & & & \\
\hline Ö6 & $X$ & & & & \\
\hline Ö7 & & & & $X$ & \\
\hline Ö8 & & & & $X$ & \\
\hline Ö9 & & & & $X$ & \\
\hline Ö10 & & & & & $X$ \\
\hline Ö11 & $X$ & & & & \\
\hline Ö12 & $X$ & & & & \\
\hline Toplam & 4 & 2 & 0 & 3 & 3 \\
\hline
\end{tabular}

Tabloya göre, siber zorbalığa maruz kalan öğrencilerin İnternet kullanım sıklığı her gün 4 saatten fazla ile her gün kullanmam arasında farklılaşmaktadır. Dolayısıyla siber zorbalığa maruz kalan her öğrencinin İnternet başında fazla zaman geçirdiği söylenemez. Haftada birkaç gün İnterneti kullanan bir öğrenci dahi siber zorbalığa maruz kalabilmektedir. 
Tablo 3. Öğrencilerin İnterneti Kullanma Amaçları

\begin{tabular}{lccccccccccccc}
\hline \multicolumn{1}{c}{ Kullanım Alanlar1 } & Ö1 & Ö2 & Ö3 & Ö4 & Ö5 & Ö6 & Ö7 & Ö8 & Ö9 & Ö10 & Ö11 & Ö12 & Toplam \\
\hline Ödev, Ders & X & & & X & X & & X & X & & X & & X & 7 \\
Sosyal Ağ (Facebook) & X & X & X & X & X & X & X & X & X & & X & X & 11 \\
Sosyal Ağ (Twitter) & X & X & & & & & X & & & & & X & 4 \\
Sosyal Ağ (Instagram) & & & X & & & & & & X & & & & 2 \\
Çevrim İçi Oyun & & X & & X & X & & & X & & & & X & 5 \\
Youtube & & X & & X & & X & & & & & & X & 4 \\
Film & & & & & & & & & & & & & \\
\hline
\end{tabular}

Öğrencilerin İnterneti kullanma amaçları ile ilgili bulgular ise Tablo3’te gösterilmiştir. Öğrencilerin İnterneti kullanım amaçlarına bakıldığında; sosyal ağların çoğunluk tarafindan kullanıldığı hemen göze çarpmaktadır. Yalnızca bir öğrenci sosyal ağları kullanmadığını ifade etmektedir. Hatta bazı öğrenciler İnterneti neredeyse sadece sosyal ağ olarak düşünmektedir. Örneğin kendisine yöneltilen soruya; Ö6 kodlu katılımc1 "Okuldan saat üç gibi dönüyordum. Gece saat bire kadar olan vaktin bir saatini ailemle geçiriyordum. Dört saatinde ders çalışıyordum. Kalan altı saatlik kısımda internet kullanıyordum. İnternette ise sadece Facebook kullanıyordum ara sıra da video izliyordum..." biçiminde yanıtlarken Ö11 kodlu katılımeı ise "Okuldan saat 4 te dönüyordum ve hemen İnternet kullanmaya başliyordum. Gece bire, ikiye kadar Facebook'ta oluyordum. Başka bir şey kullanmıyordum.” şeklinde yanıtlamıştır. İnternetin diğer kullanım amaçları ise ödev yapma, çevrim içi oyun oynama, video ve film izleme olarak belirlenmiştir.

Öğrencilerden "İnternet kullanırken velilerinden izin alıyor muydunuz?" sorusuna yedi öğrenci "Evet, her zaman izin alarak kullanıyordum." şeklinde cevap vermiştir. Dört öğrenci "Genellikle izin alırdım ama izinsiz kullandığım da oluyordu." şeklinde cevap vermiştir. Yalnızca bir öğrenci İnterneti izinsiz olarak kullandığını belirtmiştir. Genellikle öğrencilerin velilerinden izinli olarak İnternet kullandıkları görülmektedir. Ancak diğer yandan görüşmelerden ortaya çıkan bir nokta veliler İnternet kullanırken öğrencilerin neler yaptıklarını kontrol etmemeleridir. Bu durum siber zorbalık ve siber mağduriyet gibi sorunların ortaya çıkmasına adeta kapı aralamaktadır. Öğrencilerin ayrıca velilerinden gizli olarak akıllı telefonları vasitasıyla İnternete bağlanabildikleri de tespit edilmiştir.

"Gerçek yaşamınızda tanımadığınız kişilere internet ortamında arkadaşlık isteği gönderir misiniz veya tanımadığınız kişilerden gelen teklifleri kabul eder misiniz?” şeklindeki soruya öğrencilerden on biri tanımadığı kişilere istek göndermediği, biri ise ortak arkadaşı varsa tanımasa da istek gönderdiği cevabını vermiştir. Öğrencilerden beşi gerçek yaşamda tanımadığ 1 kişilerden gelen arkadaşlık isteklerini asla kabul etmediğini, yedisi ise ortak arkadaşımız varsa kabul ederim şeklinde cevap vermiştir. Kabul etme sebebi olarak; Ö9 "Bana gelen isteklerde ortak arkadaşımız varsa tanımasam da kabul ederim, sosyal ortamdaki çevrem geniş olsun diye arkadaş yaparım." Şeklinde, Ö2 ise "Oyun ortamında tanıştı̆̆ım ve samimi olduğum arkadaşlarımdan gelen istekleri gerçek yaşamda tanımasam da kabul ederim." şeklinde açıklamıştır.

\section{Siber Zorbalık Kavramı ve Siber Zorbalı̆̆a Maruz Kalma Durumunda Yapılması Gerekenler} Hakkındaki Görüşler

Siber zorbalığa maruz kalan öğrencilere siber zorbalık terimi hakkında yöneltilen "Siber 
zorbalık terimini biliyor musunuz? Daha önce hiç duydunuz mu?" şeklindeki soruya öğrencilerden biri harç diğerleri "Siz bize bundan bahsedinceye kadar hiç duymamıştık, ilk defa sizden duyduk." şeklinde cevaplar vermiştir. Sadece bir öğrenci bu terimi daha önce bir ağ sayfasında okuduğunu belirterek terimi "Sinir bozan kötü hareketler yapılan işlemlerdir." şeklinde açıklamıştır.

Siber zorbalığa maruz kalma durumunda yapılabileceklerle ilgili soruya ise katılımcıların on biri hiçbir bilgileri olmadığını, hiç araştırmadıklarını ve hukuki olarak neler yapabileceklerini bilmedikleri cevaplarını vermiştir. Bu konuda sadece bir öğrenci "Şikâyetçi olup mahkemeye verebileceğimi biliyorum..." şeklinde cevap vermiştir.

$\mathrm{Bu}$ verilerden de anlaşıldığ üzere siber zorbalığa maruz kalan öğrencilerin çoğunluğu siber zorbalıkla ilgili hiçbir bilgiye sahip değildir ve siber zorbalığa maruz kaldıklarında neler yapabileceklerini bilmemektedir.

\section{Maruz kalınan Siber Zorbalığın Niteliği ve Mağdurun Tepkileri}

Öğrencilerin hangi ortamlarda siber zorbalığa maruz kaldıklarına ilişkin veriler Tablo4'te gösterilmiştir.

Tablo 4. Öğrencilerin Siber Măgduriyet Yaşadıkları Ortamlar

\begin{tabular}{lcccc}
\hline $\begin{array}{l}\text { Sanal } \\
\text { Ortamlar }\end{array}$ & Sosyal Medya & Oyun Odaları & E- posta & Cep Telefonu \\
\hline Ö1 & $\mathrm{X}$ & $\mathrm{X}$ & & \\
Ö2 & & & & \\
Ö3 & $\mathrm{X}$ & $\mathrm{X}$ & & \\
O44 & $\mathrm{X}$ & & & \\
Ö5 & $\mathrm{X}$ & $\mathrm{X}$ & \\
Ö6 & $\mathrm{X}$ & & \\
Ö7 & $\mathrm{X}$ & & \\
Ö8 & $\mathrm{X}$ & & & \\
Ö9 & $\mathrm{X}$ & & & \\
Ö10 & $\mathrm{X}$ & 2 & 1 & 1 \\
Ö11 & 8 & & & \\
Ö12 & & & & \\
Toplam & & & & \\
\hline
\end{tabular}

Öğrencilerin siber zorbalığa uğradıkları ortamlar; sosyal Medya $(\mathrm{n}=8)$, oyun odaları $(n=2)$, eposta $(n=1)$ ve cep telefonu $(n=1)$ şeklindedir. Öğrencilerin birçoğunun sosyal medya aracılığı ile siber zorbalığa maruz kaldığı görülmektedir.

Öğrencilerin maruz kaldıkları siber zorbalığın türü ve niteliğini belirlemek için öğrencilere “ Ne tür bir siber zorbalık davranışına maruz kaldınız, nasıl oldu?” soruları yöneltilmiştir. Maruz kalınan siber zorbalığın niteliği ile ilgili veriler Tablo 5'de gösterilmiştir. 
Tablo 5. Maruz Kalınan Siber Zorbalı̆̆ın Niteliği

\begin{tabular}{|c|c|c|c|c|c|c|c|c|c|c|c|c|c|}
\hline Zorbalığın Türü & Ö1 & Ö2 & Ö3 & Ö4 & Ö5 & Ö6 & Ö7 & Ö8 & Ö9 & Ö10 & Ö11 & Ö12 & Toplam \\
\hline $\begin{array}{l}\text { Cinsel içerikli } \\
\text { hakaret ve küfür }\end{array}$ & $\mathrm{X}$ & $\mathrm{X}$ & $X$ & $\mathrm{X}$ & $\mathrm{X}$ & $\mathrm{X}$ & $\mathrm{X}$ & $\mathrm{X}$ & $\mathrm{X}$ & $X$ & $X$ & $X$ & 12 \\
\hline Tehdit & $\mathrm{X}$ & $\mathrm{X}$ & $\mathrm{X}$ & & $\mathrm{X}$ & $\mathrm{X}$ & $X$ & $\mathrm{X}$ & $X$ & & & & 8 \\
\hline $\begin{array}{l}\text { Sosyal Paylaşım } \\
\text { hesaplarının } \\
\text { şifrelerini ele } \\
\text { geçirme }\end{array}$ & & $\mathrm{X}$ & & & & & & & & & $\mathrm{X}$ & $X$ & 3 \\
\hline Aşağılama & & $\mathrm{X}$ & & $\mathrm{X}$ & & & & & & & & & 2 \\
\hline İftira & & & & $\mathrm{X}$ & & & & & & & & & 1 \\
\hline $\begin{array}{l}\text { Özel görüntüleri ele } \\
\text { gecirme }\end{array}$ & & & & & & $\mathrm{X}$ & & & & & & & 1 \\
\hline
\end{tabular}

Bütün katılımcı öğrencilerin maruz kaldığı siber zorbalık davranışlarının içeriğinde cinsel içerikli hakaret (küfür) olduğu belirlenmiştir. Buradan hareketle toplumumuzda karşıdaki insana hakaret etmek için küfrün ne kadar yaygın şekilde kullanıldığı da ortaya çıkmaktadır. Aynı zamanda öğrencilerin maruz kaldığı siber zorbalık davranışlarında; sekiz öğrencinin tehdit yoluyla, üç öğrencinin şifreleri ele geçirilerek, iki öğrencinin ise aşağılanarak siber zorbalığa maruz kaldıkları belirlenmiştir. Yine bir öğrenci iftiraya uğrama yoluyla, bir öğrenci de özel görüntülerinin ele geçirilip tehdit edilme yoluyla siber zorbalığa uğramıştır. Siber zorbalığa maruz kalan öğrencilerin bazı ifadeleri şu şekildedir:

Ö3 “....Bir hafta bana küfür etti, tehdit etti. Aramızda tartıșmalar çıttı. Bir hafta süreyle sosyal medyada karşıllklı kavga ettik. Büyük büyük kızlar toplayıp okul çıkışı geldiler. Okulun dişında karşıllklı ă̆ız kavgası ettik. Polisler geldi. Beni tutup okula getirdiler. Polisler olayı öğretmenlerime bildirdi. Ögretmenlerim de ailemi aradı ve herkesin haberi oldu."

Ö5 "....online olarak oynadiğım oyunum vardl. Oyununu bana mecburen vereceksin dedi. Nerde oturduğunu biliyorum dedi adresimi söyledi ama sokağı yanlış söyledi. Küfürler ve hakaretler etmeye başladi. Veremem kusura bakma dedim. Oraya gelir seni döverim dedi, tehdit etmeye başladi..."

Siber zorbalığa maruz kalan öğrencilerin ifadelerinden de anlaşılacağ 1 gibi sanal ortamda başlayan gerginliklere genellikle küfürleşmeye ve tehdit eşlik etmektedir ve bazı durumlarda siber zorbalık durumu gerçek hayata da yansıyabilmektedir.

Öğrencilerden bazılarının maruz kaldıkları olayları anlatırken tekrar gerginleștiği, ellerinin terlemeye başladığı, el ve kol hareketleri yaptıkları, bazılarının ağlayacak derecede duygulandıkları, bazılarının ise "hocam yine fena oldum" şeklinde söylemlerde bulundukları araştırmacı tarafindan gözlenmiştir.

Öğrencilerin maruz kaldıkları siber zorbalığa karşı verdiği tepkileri belirlemek için sorulan "Maruz kaldığınız siber zorba davranışa nasıl bir tepki verdiniz?" şeklindeki soruya öğrencilerden dokuzu hiç cevap veremediğini, durmasını söylediğini ya da kişiyi engellediğini belirtmiştir. Üç katılımcı ise "o ne dediyse ben de aynen karşıllk verdim" şeklinde ifadelerle karşı1lı verdiklerini belirtmiştir.

Öğrenci ifadelerinden uğradıkları siber zorbalık durumunda korkarak cevap vermekten kaçındıkları veya karşıdaki kişiyi engellemeye çalışarak pratik çözümler bulmaya çalıştıkları görülmektedir.

\section{Siber Zorbalı̆̆a Maruz Kalan Ö̆̆rencilerin Yardım Arama Davranışları}

Siber zorbalığa maruz kalan öğrencilerin konuyu ilk olarak kimlerle paylaştıklarını belirlemek için sorulan "Uğradığınız siber zorba davranışı ilk olarak kiminle paylaştınız?" sorusuna verilen cevaplara göre; öğrencilerden beşi olayı hiç kimseyle paylaşmadıklarını belirtmiştir. Öğrencilerden dördü olayı ilk olarak kendilerine yakın olan arkadaşlarıyla paylaştıklarını belirtirken, bir öğrenci ablasıyla paylaştığını, bir öğrenci bilgisayardan iyi anlayan bir akrabasıyla paylaştığını ve bir öğrenci ise annesi ile paylaştığını söylemiştir. Yaşadıkları 
zorbalığı kimseye anlatamayan öğrenciler buna sebep olarak korktuklarını ve utandıklarını belirtmiştir.

İfadelerden öğrencilerin kendilerine destekçi olarak daha çok arkadaşlarını düşündükleri anlaşılmaktadır. Ö3 kodlu öğrenci "İlk olarak arkadaşlarımla paylaştım. Arkadaşlarım bana destek çıkmak için hepsi ona mesajlar yazd1..." cümleleriyle bunu dile getirmektedir.

Siber zorbalığa uğradığını annesiyle paylaşan öğrenci (Ö4) ise bu durumu "Abim zaten hesabımı kontrol ediyor. Haberi oldu. Ben de anneme söyledim. Annemden gizlemem." ifadeleriyle açıklamıştır.

Görüldüğü gibi siber zorbalığa maruz kalan öğrenciler olayı ya hiç kimseyle paylaşmamakta ya da daha çok kendilerini yakın hissettikleri arkadaşlarıyla paylaşmaktadırlar. Aile bireyleri ile durumu paylaşan iki öğrenci ise aile üyelerinden destek arama düşüncesinden çok nasılsa öğreneceklerini düşüncesiyle onlara açıklama yapmıştır. Öte yandan maruz kaldıkları durumla ilgili okul rehberlik servisine başvuran ya da başvurmayı düşünen hiçbir öğrencinin olmaması düşündürücüdür.

\section{Siber Zorbalı̆̆a Maruz Kalmanın Duygusal Etkileri}

Bu bölümde siber zorbalığa maruz kalan öğrencilerin duygusal olarak nasıl etkilendikleri ve yoğun olarak hangi duyguları yaşadıkları üzerinde durulmuştur. Siber zorbalığa maruz kalan öğrencilerin duygusal olarak neler hissettiklerini belirlemek için öğrencilere sorulan "Uğradığınız siber zorbalık davranışının duygularınıza etkisi nasıl oldu?" sorusuna öğrencilerin verdiği cevaplar Tablo6'da özetlenmiştir:

Tablo 6. Siber Zorbalı̆̆ın Duygusal Etkileri

\begin{tabular}{lccccccccccccc}
\hline $\begin{array}{l}\text { Hissedilen } \\
\text { Duygular }\end{array}$ & Ö1 & Ö2 & Ö3 & Ö4 & Ö5 & Ö6 & Ö7 & Ö8 & Ö9 & Ö10 & Ö11 & Ö12 & Toplam \\
\hline Sinirlendim & $\mathrm{X}$ & $\mathrm{X}$ & $\mathrm{X}$ & $\mathrm{X}$ & $\mathrm{X}$ & & $\mathrm{X}$ & & $\mathrm{X}$ & $\mathrm{X}$ & $\mathrm{X}$ & $\mathrm{X}$ & 10 \\
Korktum & $\mathrm{X}$ & $\mathrm{X}$ & & & $\mathrm{X}$ & $\mathrm{X}$ & $\mathrm{X}$ & $\mathrm{X}$ & & $\mathrm{X}$ & & $\mathrm{X}$ & 8 \\
Tedirgin & $\mathrm{X}$ & & & & $\mathrm{X}$ & $\mathrm{X}$ & $\mathrm{X}$ & $\mathrm{X}$ & & $\mathrm{X}$ & & $\mathrm{X}$ & 7 \\
$\begin{array}{l}\text { Oldum } \\
\text { Intikam Almak }\end{array}$ & $\mathrm{X}$ & $\mathrm{X}$ & & & & $\mathrm{X}$ & & & $\mathrm{X}$ & & $\mathrm{X}$ & & 5 \\
İstedim & $\mathrm{X}$ & & & $\mathrm{X}$ & & & & & & $\mathrm{X}$ & & & \\
Üzüldüm & $\mathrm{X}$ & & & $\mathrm{X}$ & & & & & & $\mathrm{X}$ & & & \\
\hline
\end{tabular}

Tablo incelendiğinde siber zorbalığa maruz kalan öğrencilerin sinir $(\mathrm{n}=10)$, korku $(n=8)$, tedirginlik $(n=7)$, intikam $(n=5)$ ve üzüntü $(n=3)$ duygularını deneyimlediği görülmektedir. Öğrencilerin tamamına yakını sinirlendiğini ifade ederken korku ve tedirginlik de öğrenciler tarafından sık yaşanan duygulardandır. Bazı öğrenciler ise çok sinirlenerek intikam alma duygusunu yaşadıklarını belirtmişlerdir. Öğrenciler mağduriyet sonucu yaşadıkları duyguları şu şekilde ifade etmektedir:

Ö1 “...Çok kötüydü. Çok sinirlendim, korktum. Karşıma çıksa pataklayacaktım. Hiç rahat değildim... Bazen kendimi öldürmek istiyordum..."

Ö6 "Çok tuhaf bir duyguydu. Hiç rahat değildim. Her gece yarın yaparsa dediğini diye düşünüyordum. Uykularım kaçıyordu. Aileme arkadaşlarıma, ögretmenlerime ne derim diye düşünüyordum. Çok korktum. Uykusuz kaldım. Bir ay boyunca özür diledim, yalvardım..."

Anlaşıldığ gibi katılımcılar "çok kötüydü" ve "çok tuhaf bir duyguydu" gibi ifadelerle yaşadıkları durumu açıklamaya çalışmaktadır. Öğrencilerden birisi ise "Bazen kendimi öldürmek istiyordum.", bir diğeri "Evi terk edip gitmek istedim, babamın mesleğinden utandım." ve bir başkası ise "Yanımda olsa öldürürdüm!" gibi ifadeler kullanmıştır. Bu ifadeler onların yaşadığı duygu yoğunluğunu ortaya koymaktadır. 


\section{Siber Zorbalı̆̆a Maruz Kalan Öğrencilerin Aileleri ve Arkadaşları İle İlişkileri}

$\mathrm{Bu}$ bölümde siber zorbalığa maruz kalan öğrencilerin aileleri olan ilişkilerinin nasıl değiştiği, yaşadıkları olayları aileleri ile paylaşıp paylaşmadıkları, arkadaşları ile olan ilişkilerinin değişip değişmediği ve arkadaşlarının verdiği tepkiler üzerinde durulmuştur.

Siber zorbalığa maruz kalan öğrencilerin aileleri olan ilişkilerinde değişiklik olup olmadığını belirlemek için öğrencilere "Uğradığınız siber zorbalığın aile içi ilişkilerinize etkileri neler oldu?" sorusu sorulmuştur. Öğrencilerden onu yaşadığ 1 olayı ailelerinden gizlediğini, onlara anlatmadığını belirtmiştir. Öğrencilerden biri olayı ablasının bir hafta sonra öğrendiğini, onun da annesi ile paylaştığını, biri ise olayı yaşamaya başlar başlamaz annesi ile paylaştı̆̆ını söylemiştir. Genel olarak öğrencilerin yaşadıkları mağduriyet olayını aile bireylerinden özellikle anne ve babalarından gizlemeye çalıştıkları görülmektedir.

Siber zorbalığa maruz kalan öğrencilerin yaşadıkları olayları korktukları, utandıkları ve en çok da bilgisayar ve cep telefonları ellerinden alınacak diye düşündükleri için aileleri ile paylaşmadıkları ve ailelerinden gizlemeye çalıştıkları görülmüştür. Ancak olayı gizleyen öğrenciler ev içerisinde sinirli ve gergin oldukları için aile içinde çeşitli problemler yaşanabilmektedir. Bazı öğrencilerin aileleri ise zorbalık olayı yaşandıktan sonra gerçek hayata yansıdığında durumu öğrenmektedir. Şüphesiz bu durum da aile içerinde çeşitli olumsuzluklara yol açabilmektedir.

Siber zorbalığın arkadaşlık ilişkilerine etkisi incelendiğinde öğrencilerden sekizinin yaşadıkları siber zorbalık olayını arkadaşlarıyla hiç paylaşmadıklarını belirtmişlerdir. Üç öğrenci arkadaşları ile olayı paylaştıklarını ve arkadaşlarının kendine destek çıkmaya çalıştığını ifade ederken bir öğrenci ise olay bittikten sonra sadece en samimi arkadaşı ile paylaştığını belirmiştir. Yaşadığı olayı arkadaşları ile paylaşamadığını ifade eden öğrencilerden beşi zorbalık sonrasında arkadaşları ile olan ilişkilerinde çeşitli sorunlar yaşadığını belirtmiştir. Bu konuda bazı öğrencilerin ifadeleri şöyledir:

Ö1 “...Arkadaşlarımla konuşamıyordum, bahçeye çıkamıyordum, kantine bile inemiyordum. Sadece en sevdiğim arkadaşımla konuştun ama bu konuyu ona da söylemedim."

Ö4 "Bir hafta arkadaşlarımla konuşmadım. En iyi arkadaşlarımla konuşmadım, yanıma oturanlarla konuşmadım, sadece sustum..."

Ö5 "Arkadaşlarımla olan iliş̧kilerimi etkiledi. En samimi arkadaşımla bile kavga ettim. Sanki git gide saldirgan oluyorum..."

Ö7 "Sürekli bir yere bakıp dallyordum. Arkadaşlarımla daha az konuşuyordum. O süreçte kantine indim sadece korktuğum için dışarıya çıkmadım."

\section{Siber Zorbalığın Akademik Başarıya ve Okula Yașamına Etkisi}

$\mathrm{Bu}$ bölümde siber zorbalığa maruz kalan öğrencilerin akademik başarı durumları, okulda, derslerde ve ders çalışırken yaşadıkları düşünceler ve öğretmenleri ile olan ilişkiler üzerinde durulmuştur.

Öğrencilerin akademik başarılarının siber zorbalıktan etkilenip etkilenmediğini belirlemek amacıyla öğrencilere yöneltilen "Siber zorbalıktan önceki ders başarılarınız ile sonrasındaki ders başarılarınız arasında farklılık var mı?" sorusuna öğrenciler şu şekilde cevaplar vermiştir:

Ö2 "Olaydan önce yazllılarımdan 85, 90 civarında notlar aliyordum. O süreçte yazılı notlarım 35, 40 civarına düstü̈. Olaydan sonra toparlaylp tekrar eski haline döndü."

Ö4 “...Önce karnem ve notlarım iyiydi. Yaşadı̆̆ım olay tam yazll haftasina geldi. Notlarım düşmeye başladı. Geçen dönem takdir almıştım. Bu dönem teşekkür aldım. O bir hafta beni bitirdi."

Ö5 "Bu olaydan önce denemelerimde Matematikten 1-2 yanlı̧ yapıyordum. Şimdi ise 6 yanlı̧ yaptım, Türkçeden 2 yanlı̧̧ yaparken şimdi 5-6 yanlı̧̧ yapıyorum."

Verilen yanıtlardan öğrencilerin yaşadıkları mağduriyet olayı süresince ders çalışma ve derse motive olma noktalarındaki azalmanın akademik başarılarını olumsuz etkilediği görülmektedir. Özellikle siber zorbalığın uzun süre devam ettiği durumlarda akademik başarıdaki düşme daha da fazlalaşmaktadır. Öğrenciler maruz kaldıkları olay süresince derslerine konsantre olamadıklarını ve ders çalışamadıklarını belirtmektedir. Bu yüzden de 
olayın yaşandığı zaman dilimine göre bazı öğrencilerin yazılı notları düşmekte, bazılarının ise testlerdeki yanlış sayıları artmaktadır.

Öğrencilerin akademik durumlarının siber mağduriyet ile nasıl değiştiğini anlayabilmek için katılımcılara siber zorbalığın derse katılımı, devam durumunu, derse motive olmayı, uyku düzenini nasıl etkilediği soruları yöneltilmiştir (Tablo 7).

Tablo 7. Siber Zorbalı̆̆ın Akademik Duruma Etkisi

\begin{tabular}{lcccc}
\hline & $\begin{array}{c}\text { Derse } \\
\text { Kat1lım1 } \\
\text { Azaltt1 }\end{array}$ & $\begin{array}{c}\text { Devamsizlik } \\
\text { Yapmam1 } \\
\text { Sağlad1 }\end{array}$ & $\begin{array}{c}\text { Uyku Düzenimi } \\
\text { Bozdu }\end{array}$ & $\begin{array}{c}\text { Ders Motive } \\
\text { Olmamı Engelledi }\end{array}$ \\
\hline Öğrenci & 11 & 3 & 11 & 11 \\
Say1s1 & $\mathrm{X}$ & $\mathrm{X}$ & $\mathrm{X}$ & $\mathrm{X}$ \\
Ö1 & $\mathrm{X}$ 2 & $\mathrm{X}$ & $\mathrm{X}$ \\
Ö3 & $\mathrm{X}$ & $\mathrm{X}$ & $\mathrm{X}$ \\
Ö4 & $\mathrm{X}$ & $\mathrm{X}$ & $\mathrm{X}$ \\
Ö5 & $\mathrm{X}$ & $\mathrm{X}$ & $\mathrm{X}$ \\
Ö6 & $\mathrm{X}$ & $\mathrm{X}$ & $\mathrm{X}$ \\
Ö7 & $\mathrm{X}$ & $\mathrm{X}$ & $\mathrm{X}$ \\
Ö8 & & $\mathrm{X}$ & $\mathrm{X}$ \\
Ö9 & $\mathrm{X}$ & $\mathrm{X}$ & $\mathrm{X}$ & $\mathrm{X}$ \\
Ö10 & $\mathrm{X}$ & $\mathrm{X}$ & $\mathrm{X}$ & $\mathrm{X}$ \\
Ö11 & $\mathrm{X}$ & $\mathrm{X}$ & $\mathrm{X}$ & \\
Ö12 & 11 & 3 & 11 & 11 \\
Toplam & & & & \\
\hline
\end{tabular}

Siber zorbalığa maruz kalan öğrencilerden on biri, siber zorbalığın okulda derslere katılımlarını olumsuz yönde etkilediğini belirtmiş̧tir. Bir öğrenci ise siber zorbalığın derse katılım üzerinde etkili olmadığını belirtmiştir. Bu konuda katılımcıların ifadeleri şu şekildedir:

Ö1 "O konudan kurtulamiyordum. Sürekli dallyordum..."

Ö4 "O süre hiç derse katılmadım, hiç ders dinlemedim, teneffüse bile çıkmadım. Hiç konuşmadım."

Ö6 "Derslerde kafam hep ya dediğini yaparsa diye ondaydl. Bir ay boyunca hiç derse katılmadım..."

Ö11 "O süreçte hiç derslere katılmadım. Hep sinirliydim. Sürekli ne yaparım diye düşündüm."

Öğrencilerin de ifadelerinde belirttiği gibi siber zorbalığa maruz kalma öğrencilerin derse katılımlarını ve derslerdeki motivasyon düzeylerini olumsuz şekilde etkilemiştir.

Öğrencilerin devamsızlık sorunu yaşayıp yaşamadıkları ile ilgili soruya; öğrencilerden dokuzu devamsızlık yapmadığını belirterek cevap vermiştir. Üç öğrenci ise iki, üç gün devamsızlık yaptıklarını belirtmişlerdir. Öğrencilerden ikisi tehdit edilip korktuğu için devamsızlık yaptığını, biri ise geceleri uykusuz kaldığı için sabahları geç kaldığını veya hiç okula gitmediğini belirtmiştir.

Öğrencilerin "siber zorbalık süresinde uykusuzluk problemi yaşadınız mı" sorusuna on biri "evet, yaşadım" cevabını vermiş, bir öğrenci ise uykusuzluk problemi yaşamadığını belirtmiştir. Öğrencilerin bazılarının verdikleri cevaplar şu şekildedir;

Ö3 "O süreçte geceleri çok uykusuz kaldım, saatlerce uyumadım. Bunalıyordum. Camı açıp hava almak istedim. Dlşarlya çıkıp gezmek istedim. Evine gidip onu boğayım diye düşündüm, çünkü çok sinirlenmiştim." 
Ö5 "Normalde saat onda yatarım. Bu olay olunca birden sonra uyumaya başladim. Söyledikleri aklıma geliyor. Kafama vurmaya başliyorum. Gözlerimi kapattyorum. Çok sinirleniyorum..."

Ö7 "O süreçte geceleri korktum uyuyamadım. Yattı̆̆ım odayı da değiştirdim. Evini bulacağım seni takip edeceğim diyordu korktum odamda yatamadım..."

Ö8 "Bazen rüyama giriyordu, korkuyla uyanıyordum. Uyaninca tekrar uyuyamiyordum onи düşünüyordum..."

Öğrencilerin siber zorbalığa maruz kaldıkları süreçte ciddi ölçüde uykusuzluk problemi yaşadıkları, aynı zamanda korkuya kapıldıkları ifadelerinden açıkça anlaşılmaktadır. Bu durumun öğrencilerin derslerdeki performanslarını düşüreceği öngörüsünde bulunulabilir.

"Derse motive olma" ile ilgili soruya öğrencilerden biri hariç tamamı motivasyon konusunda sıkıntı yaşadıklarını belirtmiştir. Öğrenciler bu durumu şu ifadelerle anlatmıştır:

Ö2 "Öğretmenlerimle, özellikle sosyal bilgiler öğretmenimle gergin olduğum için sorunlar yaşadım..."

Ö8 "Kalabalı olduğunda, arkadaşlarım olduğunda unutuyorum, ama yalnız kaldığımda hep aklima geliyor, ilk zamanlar yalnız kalamıyordum hiçbir yerde..."

Ö10 "Özellikle olayı yaşadığım aralar hiç motive olamıyordum, dalıp gidiyordum. Bir daha böyle bir şey olursa direk polise giderim. Çok ağır küfüler ediyorlar..."

Ö11 "Derslerde hiç ögrretmeni dinlemedim, çünkü aşır derecede sinirliydim ve çok düşünüyordum."

Yanıtlardan siber zorbalığa maruz kalan öğrencilerin derse motive olma güçlüğü yaşayabildikleri, derslerde gergin ve sinirli oldukları için öğretmenleri ile çeşitli sorunlar yaşayabildikleri görülmektedir. Öğrenciler yaşadıkları süreci "Hiç kimsenin başına gelmesin, bir daha böyle bir şey olursa direk polise giderim, hiçbir yerde yalnız kalamıyordum" gibi ifadelerle de anlatmaya çalışmışlardır.

\section{Tartışma ve Sonuç}

Siber zorbalık; bilgi ve iletişim teknolojilerinin kullanımı yoluyla bir kişi veya bir grup tarafindan başkalarına zarar vermek amacıyla yapılan kasıtlı, tekrar eden ve saldırgan davranışlardır. Çocuk ve ergenlerde zorbalık davranışının okul içerisinde ve okul dışındaki nedenlerini incelemek amacıyla yapılan araştırmalar zorbalığın çocuk ve ergenler üzerinde olumsuz etkilerinin olduğunu göstermektedir. Buna göre çocuk ve ergenlerin kültürü, milleti veya coğrafi konumu ne olursa olsun; zorbalık davranışının çocuk ve ergenler üzerinde gelişim yaşına, kültürel ve bireysel algıya göre az veya çok olumsuz etkilerinin olduğu söylenebilir (Ayas, 2010).

Bireylerin sanal ortamda istenmeyen davranışlara maruz kalmaları az rastlanan bir durum değildir. Örneğin Arıcak ve diğerleri (2008), 269 öğrenci üzerinde yürüttükleri bir araştırmada öğrencilerin \% 36'sının İnternette istenmeyen ve rahatsız edici durumlarla karşı karşıya kaldığını belirlemiştir.

Ortaokul öğrencilerinden siber zorbalığa maruz kalanların durumlarının çeşitli açılardan incelenmesini amaçlayan bu çalışmada elde edilen bulgulara göre araştırmaya dâhil edilen öğrenciler siber zorbalığa sosyal ağ, çevrimiçi oyun, elektronik mesajlaşma gibi çeşitli sanal ortamlarda maruz kalmaktadır. En çok siber zorbalık olayı ile sosyal ağlarda karşılaşılmaktadır. Siber zorbalığın niteliği küfür, tehdit, hesabı ele geçirilme, iftiraya uğrama, aşağılanma, özel görüntülerin ele geçirilmesi gibi farklı biçimlerde olabilmektedir. Ancak ne yazık ki birçok öğrencinin etkilendiği bu olguyla ilgili olarak öğrenciler ne yeterli farkındalık düzeyindedir ne de yeterli ve uygun başa çıkma bilgisine sahiptir.

Bulgulara göre bazı durumlarda sanal ortamda başlayan siber zorbalık durumu gerçek hayata da yansıyabilmekte, siber zorbalık geleneksel zorbalığa dönüşebilmektedir. Bu durumla ilgili olarak alan yazında da geleneksel zorbalıkla siber zorbalık davranışlarını sergileme arasında bir paralellik olduğu yönünde bulgulara rastlanmaktadır (Paez, 2016).

Yine bulgulara göre siber zorbalığa maruz kalan öğrencilerin çoğunluğu korktukları ve utandıkları için yaşadıkları olayları ailelerinden gizlemektedir. Ancak öğrencilerin siber zorbalığa uğradıklarını ailelerinden saklamalarının bir diğer sebebi de bilgisayar ve cep telefonlarının ellerinden alınması endişesi olabilmektedir. Çünkü Patchin ve Hinduja'ya (2012) 
göre çocuklar, ergenler ve gençler arasında çevrimiçi olmak; sosyalleşmek ve iletişime açık olmak anlamlarına gelmektedir. Siber zorbalığa maruz kalan çocuk, ergen ve gençler ailelerinin telefonlarına ve bilgisayarlarına el koyacakları ve kullanımına izin vermeyecekleri konusunda endişelenmekte ve siber zorbalık durumunu ifade etmek istemeyebilmektedir.

Ancak mağdurlar her ne kadar başlarına gelen bu durumu gizleseler de ev içerisinde sinirli ve gergin oldukları için aileleriyle çeşitli sorunlar yaşayabilmektedir. Hatta bulgulara göre bazı öğrencilerin aileleri, çocuklarının yaşadıklarını ancak siber zorbalık geleneksel zorbalığa dönüştükten sonra öğretmenlerden ya da polisten öğrenmektedir.

Öğrenciler siber zorbalıkla daha çok tek başlarına baş etmeye çalışmaktadır. Yardım arayışına giren öğrencilerin ilk başvurdukları adres ise, en yakın arkadaşlarıdır. Ancak yaşadıklarını paylaşamayanlar gergin ve endişeli olduklarından dolayı arkadaşlarıyla iletişim kurmada bazı sıkıntılar yaşayabilmektedir. Elde edilen bulgulara göre öğrenciler ailelerini ve öğretmenlerini ve rehber öğretmenlerini bu konuda kendilerine yardım edebilecek kişiler olarak düşünmemektedir. Aslında gerek ailelerin gerekse öğretmen ve rehber öğretmenlerin öğrencilere desteği son derece önemlidir. Çünkü Wang ve arkadaşları (2009), aileleri tarafından kontrol edilen ve ailelerinin desteği alan ergenlerin geleneksel zorbalık ve siber zorbalık davranışlarını daha az sergilediklerini belirlemiştir. Ancak ne yazık ki araştırmalara göre öğrenimleri sırasında siber zorbalık konusunda gerekli donanımı kazanmaları beklenen bilişim teknolojileri öğretmen adayları dahi siber zorbalıkla ilgili durumları belirleme, değerlendirme ve bu durumlarda öğrencilerine destek olma noktasında yeterli bilgiye sahip değildir (Kavuk, Bulu ve Keseri, 2016).

Sonuçlarda siber zorbalığa uğramanın öfke, korku, tedirginlik gibi olumsuz duyguları artırdığı görülmektedir. Öte yandan siber zorbalığa maruz kalma sonucunda depresyon belirtileri sergileme yüzdesi ise \%49'a kadar ulaşabilmektedir (Edwards, Kontostathis ve Fisher, 2016). Siber zorbalığa maruz kalan öğrencilerin tamamına yakını öfkelendiklerini belirtmiştir. Hatta bazı katılımcılar yaşadıkları öfke sonucu intikam almak istediklerini belirtmiştir. Genel zorlama kuramı, bireylerin stres, öfke gibi durumlar yaşamalarının sonucunda olumsuz duygulara geliştirdiklerini ve sapkın davranışlar sergilemeye daha açık olduklarını ifade etmektedir (Agnew, 1992). Paez (2016), siber zorbalığ1 zorlama kuramına göre incelediği araştırmasında zorlanarak olumsuz duygular deneyimlenen ergenlerin siber zorbalık davranışlarını sergilemeye daha yatkın olduğu bulgusuna ulaşmıştır.

Aşırı bir durum olarak siber zorbalığın mağdurda intihar etme düşüncesi dahi uyandırabilmesi araştırmanın ilginç bulgularından biridir. Bu bulgular Üneri'nin (2012) zorbalığın öğrenciler için ciddi bir travma olduğu, etkilerinin yaşam boyu devam ettiği ve olumsuzluklarının topluma da yansıdığı biçimindeki görüşleriyle uyuşmaktadır. Burada elde edilen bulgular konuyla ilgili diğer birçok araştırmanın bulgularıyla tutarlık göstermektedir. Birçok araştırmacıya göre siber zorbalık çocuklarda ve ergenlerde; kızgınlık, üzüntü ve sinirlilik, okul devamsızlığı, akademik başarılarda düşüklük gibi olumsuz etkilere yol açmaktadır. Aynı zamanda depresyon, düşük benlik saygısı ve intihar gibi düşüncesinin de siber zorbalığın olumsuz etkileri arasında yer aldığı belirtilmiştir (Patchin ve Hinduja, 2006; Şahin, Sarı, Özer ve Er, 2010; Arıcak, 2011). Edwards, Kontostathis ve Fisher (2016) ise alan yazın taramasına dayandırdıkları çalışmalarında siber zorbalığa maruz kalma sonucunda intihar etme düşüncesine kapılma yüzdesinin farklı çalışma gruplarında \%8 ile \%23 arasında değişirken, intihar girişiminde bulunmanın \%6 ile \%11 arasında değiştiği bulgularına ulaşmıştır.

Öte yandan araştırmanın sonuçlarına göre öğrenciler maruz kaldıkları siber mağduriyet olayı süresince derslerine yoğunlaşma ve ders çalışmada sıkıntılar yaşamaktadır. Siber zorbalık mağdurların notlarının düşmesine, testlerde yapılan yanlışların artmasına sebep olabilmektedir.

Şüphesiz veli, öğretmen ve rehber öğretmenlerin siber zorbalık ve siber mağduriyete yönelik farkındalıkları bu tür olumsuz durumların etkilerinin azaltılmasında etkili olacaktır. Öğretmenler öğrencilerini gözlemleyerek güdülenme, derse odaklanma, akademik başarı gibi değişkenlerde belirgin farklar gördüğü öğrencilerini izlemeli, gerektiğinde veli ve okul rehberlik servisi ile işbirliği yapabilmelidir. Diğer taraftan öğrencilere siber zorbalıkla ilgili bilgi verilmeli, bu tür mağduriyetin herkesin başına gelebileceği açıklanarak siber zorbalıkla baş etme yolları 
gösterilmelidir. Çünkü zorbalığa maruz kalan birçok öğrenci nasıl bir tutum sergileyeceği konusunda fikir sahibi değildir ve öğrenciler kendi geliştirdikleri sağlıksız yöntemlere başvurarak ya da içinde bulundukları duruma duyarsızlaşarak tepki vermektedirler (Üneri, 2012).

Hem siber zorbalığa maruz kalmayı hem de bu zorbalığa ister istemez bulaşmayı azaltmak amaciyla alınabilecek önlemlerden biri ise öğrencilerin anonim kimlikler üzerinden yapılan iletişimden uzak durmalarını sağlamak olabilir. Çünkü Nakano ve diğerleri (2016), sosyal ağlarda sorulan sorular ve verilen yanıtlarla ilgili araştırmalarında anonim kimlikte olan kullanıcıların daha fazla saldırgan tutum sergiledikleri ve kullanıcıların kendilerine anonim kimlikle sorulan sorulara daha fazla saldırgan yanıtlar verdikleri bulgularına ulaşmışlardır. Ancak araştırmacılar bu saldırgan tutum ve davranışların her durumda zorbalık yapmak anlamına gelmediğini, bazı durumlarda kişilerin kendinin ya da başkalarının uğradığı saldırganlığa tepki vererek savunma yapmaya çalıştıklarını belirtmektedir.

Velilerin de özelde bu konuda genelde bilgi ve iletişim teknolojinin kullanımı konusunda bilgilendirilmesi yine büyük önem arz etmektedir. Veliler çocuklarının bilgi ve iletişim teknolojileri kullanma durumlarını kontrol etmeli, bu konuda kurallar koymalı, onların özellikle sosyal ağ ve çevrimiçi oyun ortamlarındaki davranışlarını ve iletişim kurduğu kişi ve profiller yakından gözlemelidir.

Sorunla ilgili alınabilecek önlemlerden diğerleri ise öğrencilere empati kurma becerisinin ve bazı değerlerin kazandırılmaya çalışılması olabilir. Çünkü bazı duyuşsal özellik ve değerlere sahip olma ile siber zorbalık duyarlığı arasında ilişki bulunmaktadır. Bu konuda yürütülen araştırmalardan birinde bilişsel ve duyuşsal empatinin ergenlerde geleneksel ve siber zorbalıkla negatif korelasyon verdiği bulgusuna ulaşmıştır (Del Rey vd., 2016). Diğer bir çalışmada ise Dilmaç ve diğerleri (2016) barış ve arkadaşlık değerlerinin yükselmesi durumunda siber zorbalığa yönelik duyarlığın da yükseldiğini belirlemiştir.

Sonuç olarak yürütülen bu araştırmada siber zorbalığın duygu durumuna etkisi yönünde elde edilen bulguların daha önceleri yürütülmüş olan çalışmalarla paralel olduğu görülmektedir. Çalışmada ayrıca siber zorbalığın akademik başarı ve okul yaşamına etkisi incelenerek ortaya konmuştur. Bu araştırmanın belki de en anlamlı sonucu öğrencilerin siber zorbalık terimi hakkında bilgi sahibi olmamaları, böyle bir mağduriyet durumunda ne yapacaklarını ve nasıl davranacaklarını bilememeleridir. Ayrıca katılımcı öğrencilerin uğradıkları siber mağduriyetle ilgili olarak aile, öğretmen ve rehber öğretmenlerini kendilerine yardım edebilecek bireyler olarak görmemeleri düşündürücü bir sonuç olarak karşımıza çıkmaktadır.

\section{Kaynakça}

Agnew, R. (1992). Foundation for a general strain theory of crime and delinquency. Criminology, 30(1), 47-88. doi:10.1111/crim.1992.30.issue-1

Arıcak, O.T. (2011). Siber zorbalık: Gençlerimizi bekleyen yeni bir tehlike. 12.07.2015 tarihinde http://www.kariyerpenceresi.com adresinden alınmıştır.

Arıcak, T., Siyahhan, S., Uzunhasanoğlu, A., Sarıbeyoğlu, S., Çıplak, S., Yılmaz, N. \& Memmedov, C. (2008). "Cyberbullying among Turkish adolescents". Cyber Psychology \& Behavior, 11(3), 253-262.

Ayas, T. (2010). Okullarda yaygin sorun olan zorbalığı önlemek. (1.Baskı) Ankara: Maya Akademi Yayın Dağıtım.

Belsey, B. (2004). Cyberbullying an emerging threat to the always on generation. Retrieved July 15, 2015 at http://www.cyberbullying.ca/pdf/Cyberbullying_Article_by_Bill_Belsey.pdf

Beran, T. \& Li, Q. (2007). The relationship between cyberbullying and school bullying. Journal of Student Wellbeing, 1(2), 15-33.

Del Rey, R., Lazuras, L., Casas, J. A., Barkoukis, V., Ortega-Ruiz, R., \& Tsorbatzoudis, H. (2016). Does Empathy Predict (Cyber) Bullying perpetration, and how do age, gender and nationality affect this relationship?. Learning and Individual Differences, 45, 275 - 281.

Dilmaç, B., Yurt, E., Aydın, M., \& Kaşarcı, İ. (2016). Predictive relationship between humane values of adolescents cyberbullying and cyberbullying sensibility. Electronic Journal of Research in Educational Psychology, 14(1), 3-22. 
Edwards, L., Kontostathis, A.E., \& Fisher, C. (2016). Cyberbullying, race/ethnicity and mental health outcomes: A review of the literature. Media and Communication, 4(3), 71-78. doi: $10.17645 / \mathrm{mac} . v 4 i 3.525$

Erdur-Baker, Ö., \& Kavşut, F. (2007). A new face of peer bullying: Cyber bullying. Journal of Euroasian Educational Research, 27, 31-42.

Erdur-Baker Ö., \& Tanrıkulu, İ. (2010). Psychological consequences of cyber bullying experiences among Turkish secondary school children. Procedia Social and Behavioral Sciences, 2, 2771-2776.

Gabriel R. Paez (2016): Cyberbullying among adolescents: A general strain theory perspective. Journal of School Violence, August, 1-12. doi: 10.1080/15388220.2016.1220317

Johnson, C.L. (2011). An examination of the primary and secondary effects of cyber-bullying: Development and testing of a cyber-bullying moderator/mediator model. $\mathrm{PhD}$ thesis. Michigan: Graduate School of Wayne State University.

Kavuk, M., Bulu, S., \& Keser, H. (2016). A study of pre-service information and communication teachers' efficacy levels for analyzing and responding to cyberbullying cases. World Journal on Educational Technology, 8(2), 91-97.

Kınay, H. (2012). Lise Öğrencilerinin siber zorbalık duyarlılı̆̆ının riskli davranış, korumacı davranış, suça maruziyet ve tehlike algısı ile iliş̧kisi ve çeşitli değişkenler açısından incelenmesi.Yayınlanmamış yüksek lisans tezi. Sakarya: Sakarya Üniversitesi Eğitim Bilimleri Enstitüsü.

Kowalski, R.M., \& Limber, S.P. (2007). Electronic bullying among middle school students. Journal of Adolescent Health, 41(6), 22-30.

Nakano, T., Suda, T., Okaine, Y., \& Morre, M.J. (2016). Analysis of cyber aggression and cyberbullying in social networking. Tenth International Conference on Semantic Computing. California USA: February 3-5, 337-341.

Patchin, J.W., \& Hinduja, S. (2006). Bullies move beyond the schoolyard: A preliminary look at cyber bullying. Youth Violence and Juvenile Justice, 4(2), 148- 169.

Slonje, R. \& Smith, K.P. (2008). Cyberbullying: Another main type of bullying. Scandinavian Journal of Psychology, 49, 147-154.

Şahin, M., Sarı, S. V., Özer, Ö. ve Er, S. H. (2010). Lise öğrencilerinin siber zorba davranışlarında bulunma ve maruz kalma durumlarına ilişkin görüşleri. SDÜ Fen Edebiyat Fakültesi Sosyal Bilimler Dergisi, 21, 257-270.

Türkoğlu, S. (2013). Ergenlerin problemli İnternet kullanımları ile siber zorbalık eğilimleri arasındaki ilişkinin incelenmesi. Yayınlanmamış yüksek lisans tezi. İstanbul: Marmara Üniversitesi Eğitim Bilimleri Enstitüsü.

Üneri, Ö. Ş. (2012). Akran zorbalığı: çocuklarda zihinsel ve fiziksel gelişimi bozuyor. Popüler Psikiyatri, 65, 34.

Wang, J., Iannotti, R.J., \& Nasel, T.R. (2009). School bullying among adolescents in the United States: Physical, verbal, relational, and cyber. Journal of Adolescent Health, 45(4), 368375. doi:10.1016/j.jadohealth.2009.03.021

Willard, N. (2007). Educator's guide to cyberbullying and cyberthreats. Retrieved July 18, 2015 at https://education.ohio.gov/getattachment/Topics/Other-Resources/School-Safety/Safeand-Supportive-Learning/Anti-Harassment-Intimidation-and-BullyingResource/Educator-s-Guide-Cyber-Safety.pdf.

Yaman, E., Eroğlu, Y. ve Peker, A. (2011). Başa çıkma stratejileriyle okul zorbalı̆̆ ve siber zorbalı. (1. Bask1). İstanbul: Kaknüs Yayınları.

\section{Extended Abstract \\ Introduction}

The rapid development of communication technologies has had deep impacts on human-human communication. Studies revealed that improper use of these technologies may have various negative side effects on social, cognitive and affective development of children and adolescents. 
That's why, determination of and taking measures against these side effects are important to individuals and society.

Transition of traditional bullying to electronic means has created a phenomenon called as cyber bullying. Cyber bulling consists of aggressive and repetitive behaviours exposed at electronic media against others in other to give harm and hurt them. Cyber bulling may appear in many forms as insulting, threatening, retailing rumour, sharing private images, sharing private information, signing up fake accounts or hacking to others' accounts. According to research, being exposed to cyber bulling is not a rare event among children and adolescents.

\section{Method}

The main purpose of this study is to examine experiences of secondary school students, who were exposed to cyber bullying, from social, emotional and academic achievement viewpoints. The current study has been conducted in a secondary school, located in Nevsehir. The study has been planned and carried out as a qualitative case study. Twelve students were selected by using criterion sampling, a purposive sampling method. Students who were enrolled in secondary school, exposed to cyber bulling and volunteered to participate in the study have been selected. Data was obtained through semi-structured interviews. Interviews were sound recorded and transcribed before analysis. Significant signs in body language of respondents were also noted by researcher. Average duration of the interviews was calculated as 13 minutes. The interview form was prepared after an extensive literature search and it was piloted through pre-interviews. The final form consisted of 29 open ended items. Data obtained was analysed using descriptive analysis technique within the framework of pre-determined themes. The themes of the study are about Internet usage of participants, their opinions on cyber bullying, response of participants to cyber bulling, type of cyber bullying being exposed to, help seeking behaviours of participants, communication of participants with family members and friends during and after cyber victimization, emotional and academic effects of cyber victimization.

\section{Results and Discussion}

The results of the study showed that participants were aware of neither the term "cyber bullying" nor how to respond properly to cyber bullying. It seems that parents of those students who were exposed to cyber bullying did not control their children adequate enough while they were using information and communication technologies. It was also found that students were exposed to cyber bullying mostly in social networks and online game environments and mostly by swearwords and threats. Participants generally didn't share these experiences with other people. Instead, they gave preference to coping alone with the situation. Most of the participants preferred not sharing cyber victimization events even with family members because of shame and fear, showing that they did not trust their parents' support or they were scared of being left without their smart phones or computers. In some cases, parents learnt about the situation from other sources such as teachers or even police.

It was revealed that students who were exposed to cyber bullying experienced negative emotions such as fear, anger, and nervousness. Victims tended to show nervous and tense behaviours at home and school causing communication problems with family members, teachers and friends. Some participants stated about a wish of revenge.

Lessened amount of study time and reduced rate of academic achievement were also reported. Cyber victims stated that they experienced difficulties of focusing, listening to lessons and studying. In some cases dramatic decreases in grades were also reported.

Participant students stated they experienced insomnia and monophobia during and after exposure to cyber bullying. Fear of going out, doubts about other people, difficulty in communicating with others and even thought of suicide are also among findings.

We certainly think that raising awareness of families, teachers, and counsellors will help in decreasing numbers and side effects of cyber bullying. Teachers should continuously observe students' behaviours and academic achievement and cooperate with parents and school counselling service whenever necessary. On the other hand, training of students about cyber 
bullying and cyber victimization is another vital issue. Students should learn these two terms and should know how to avoid from and respond to cyber bulling. Otherwise they may accept being a cyber-victim desperately or they may try to cope with situation by applying to ineffective or even risky methods. Informing parents on cyber bulling is also a vital precaution. As suggested in many studies, parents should continuously monitor and control ICT usage of their children. They should formulate and apply rules regarding usage of information and communication technologies, especially for social networks and online games. 